\title{
El Sistema de Transporte en el Cono Sur: LOS NuEVOS PROYECTOS
}

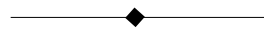

\section{RESUMEN}

En el marco de la reestructuración económica internacional y de los procesos de integración regional, y en función de la demanda de la aceleración de la circulación de mercadería, está surgiendo una serie de proyectos de infraestructura de transporte con características que difieren a los encargados en épocas anteriores, y que están produciendo una nueva configuración territorial.

El presente trabajo tiene por objetivos analizar la evolución del sistema de transporte en el Cono Sur y, en el marco de los procesos de integración y la reestructuración económica, las nuevas demandas que se plantean y cuáles son las transformaciones que a partir de la concreción de estas nuevas obras se están produciendo sobre los territorios involucrados. Se analiza el sistema de transporte regional en relación con la estructuración del territorio, en los países que integran el Mercosur (Argentina, Brasil, Uruguay y Paraguay), así como también en los asociados (Bolivia y Chile).

A partir del relevamiento y del diagnóstico de la situación, y junto a los nuevos proyectos formulados, se reflexiona sobre la tendencia a la reconcentración de la infraestructura y las inversiones, con la consiguiente desigualdad territorial que se profundiza reproduciendo la fragmentación territorial en regiones que reciben nuevos proyectos, que obedecen estos últimos a objetivos externos sin considerar sus impactos sobre el conjunto de los territorios.

\section{ABSTRACT}

In the context of the international restructuration of the economy and the regional integration process, according to the claim of accelerating the trade circulation, there is emerging a kind of transporting subestructure project with different characteristics from other times, which are producing a new territorial configuration.

* Investigadora CONICET-CEUR. Magíster en Planificación Urbana y Regional, Universidad de Buenos Aires. maschw @fadu.uba.ar 
The present study has the objective to analyze the evolution of the transportation system in the South Cone and, in the context of the integration process and the economic restructuration, the new demans and which are the transformations of the involved territories since the concretion of this new actions. It is analyzed the regional transportation system related to the territory estructuration in those countries integrating the Mercosur (A rgentina, Brasil, Uruguay and Paraguay), as well as in the associated nations (Bolivia and Chile).

Based on the relief and diagnosis of the situation, and considering those new projects, we make a reflection about the tendency to reconcentrate the subestructure and the inversions, with the following territorial inequality that gets deeper and reproduces the territorial fragmentation in regions that receive the new projects obeying to external goals without considering the global impact in the territories' group.

\section{INTRODUCCIÓN}

En los años sesenta, durante el periodo de vigencia del modelo de industrialización por sustitución de importaciones, los grandes emprendimientos estuvieron orientados al mercado interno, con el abastecimiento de productos primarios y energía para los grandes centros consumidores y productores, hacia el interior de cada uno de los países.

En lo que respecta a los servicios de infraestructura, el Estado ha sido el proveedor dominante durante la mayor parte del siglo $\mathrm{XX}$, con el argumento de que las imperfecciones de los mercados de capitales privados junto a la propia naturaleza de las obras (generalmente operan como monopolios naturales), requieren inversiones cuantiosas con costos no recuperables, y tienen un periodo de gestación y de recuperación de la inversión muy largo (BID-INTAL, 1996).

En el pasado, la política en general ha sido, en algunos casos como en la infraestructura vial, la de desligar los costos del servicio de los beneficios que producen. En otros, como la energía, las comunicaciones y el transporte ferroviario, el precio del servicio no siempre ha sido compatible con el costo económico de la operación.

En la década de los setenta entró en crisis el modelo de industrialización por sustitución de importaciones vigentes hasta entonces en los países de mayor industrialización relativa en el Cono Sur, fundamentalmente Brasil y Argentina. 
En la etapa actual, con la estrategia de crecimiento económico y búsqueda de la reinserción económica externa en el marco del proceso de internacionalización y globalización de la economía mundial, se intenta estructurar los territorios según el actual modelo neoliberal, que requiere un espacio integrado orientado a cubrir las demandas de los mercados externos. Se refuerzan los esquemas de integración existentes o se crean nuevas alianzas comerciales, generalmente con los países vecinos, que en conjunto constituyen un área comercial natural.

A diferencia de los esquemas tradicionales de integración -que se caracterizaban por una alta protección e intervención de Estado-, los nuevos esquemas tienen como objetivos complementar la apertura comercial y convertirse en instrumento que facilite la expansión y diversificación de las exportaciones y la inserción competitiva en la economía mundial, supuestamente como requisito indispensable para lograr la "modernización productiva" y el desarrollo económico en esta época de globalización de los mercados.

El Mercosur fue concebido con una orientación aperturista y está enmarcado en un esquema institucional flexible. Así se generan demandas de aceleración de la circulación de bienes y servicios por las nuevas formas de producir y comercializar. De esta manera, el movimiento de la integración económica puso en evidencia la necesidad de establecer conexiones entre las áreas marítimas y fluviales. Esto se manifestó a través del interés de los países en establecer corredores bioceánicos, en el sentido este-oeste, pensando en la salida de productos hacia otros continentes por vía marítima, y con menor peso, vinculaciones norte-sur.

De acuerdo con el model o exportador, las estrategias que se están imponiendo para la viabilización de éstas son parte de las estrategias más globales definidas en el marco del propio proceso de integración regional, impulsadas en algunos casos desde los mismos organismos internacionales. Cuentan, por lo tanto, con objetivos y plazos concretos y recursos aportados por actores cada vez menos locales, nacionales o incluso regionales. En algunos de estos casos son parte de políticas definidas a escala continental y con recursos de organismos internacionales. 
En concordancia se ha adoptado, a mediados de los años ochenta, un nuevo paradigma de desarrollo en A mérica Latina, que incluye una severa disciplina fiscal y que aún hoy continúa reduciendo el papel del Estado en la formación de capital y creando condiciones para la creciente participación del sector privado.

La reforma del Estado incluyó tanto la desregulación del sector privado como la aplicación de reformas financieras y monetarias, la reducción del empleo y privatización de empresas públicas, y la descentralización de parte de las funciones del Estado nacional hacia los gobiernos regionales. El sector privado aparece como nuevo e importante actor en esta área. De hecho, a partir de la aplicación de las reformas económicas se viene observando una participación creciente del sector privado tanto en la construcción como en la operación de proyectos de infraestructura. La capacidad de los distintos sectores de la infraestructura de atraer al sector privado varía ampliamente. Los gobiernos han adoptado distintas estrategias para atraer la participación del privado en el desarrollo, financiamiento, mantenimiento y operación de los servicios de infraestructura. Esto puede asumir distintas modalidades que van desde la privatización total hasta la conversión de empresas públicas en sociedades por acciones por sectores estratégicos, pasando por la coparticipación en distintas formas de asociación, tales como contratos de operación y mantenimiento, arrendamiento, concesión y construcciónoperación-transferencia, con distintos niveles de participación de los sectores público y privado.

El nuevo rol que asume el Estado en el marco de la reformulación de sus funciones y la disminución de su capacidad de regulación, incide sobre la modalidad de gestión de las obras de infraestructura, en la inserción del sector privado en ellas y en la disposición de mecanismos destinados a la satisfacción de las demandas sociales que estas nuevas implantaciones producen, tanto en cuanto al nivel de satisfactores urbanos como de atención a la problemática de empleo, salud, educación, seguridad, ambiental, migraciones, etcétera.

Los gobiernos del Cono Sur han ejecutado proyectos de inversión en transporte y energía, recurriendo típicamente a una combinación 
de préstamos de organismos internacionales de desarrollo, recursos propios y transferencias internas en el sector.

Más recientemente, tanto los gobiernos centrales como algunas empresas estatales, han logrado acceder a los mercados de capitales internacionales, ampliando significativamente su capacidad para financiar proyectos de inversión de magnitud importante.

\section{EL SISTEMA DE TRANSPORTE EN LA REGIÓN DE ESTUDIO}

Desde la primera etapa de integración física, el sistema de transporte se ha estructurado, generalmente, con corredores de transporte que se inician en los principales puertos, penetrando gradualmente al interior del continente. Las razones de ello son los patrones históricos de asentamiento y la concentración geográfica de las actividades productoras de bienes de exportación, agrícolas y mineros, que impulsaron el desarrollo de los ferrocarriles a fines del siglo pasado.

Con la diversificación de la producción y el proceso de industrialización posterior a la segunda guerra mundial, la red de carreteras se desarrolló rápidamente, compitiendo con las líneas ferroviarias e interconectando los crecientes centros urbanos industriales, de tal manera que el transporte por carretera es el modo dominante, tanto para pasajeros como para cargas.

El desarrollo de infraestructura de integración física entre países del Cono Sur, se realizó en sentido norte-sur y se concentró en las áreas costeras. La evolución del modo carretero se real izó en desmedro del transporte ferroviario y fluvial. De hecho, no existen sistemas nacionales modernos y eficientes de ferrocarriles, y por lo general, no se interconectan los sistemas nacionales.

Los sistemas nacionales de transporte en el Cono Sur se desarroIlaron de manera relativamente aislada, con criterios nacionales e internos a cada país. Las interconexiones entre carreteras se restringieron a los pasos fronterizos, que atendían las necesidades mínimas de comunicación entre países vecinos. Desde mediados de siglo, se ha intentado conectar los sistemas nacionales de carreteras, 
siempre limitados a aquéllos que se justifiquen desde las relaciones comerciales, y tratando de mantener en cada país la protección de sus actividades productivas en relación con el comercio intrarregional.

Los primeros proyectos de integración física en la cuenca del Plata, comenzaron a ser desarrollados a partir de 1933, con los primeros estudios para la construcción del puente Uruguaiana-Paso de los Libres. Este puente, terminado en $1955,{ }^{1}$ le siguió la construcción del Puente Puerto Iguazú-Foz do Iguaçú.

A mediados de siglo, Argentina estaba conformada por varias "islas" (Fundación F. Ebert, 1991) que no se conectaban entre sí, separadas por grandes espacios vacíos. Este país se volcaba hacia Buenos Aires y desde allí con el resto del mundo, y Brasil hacia el eje formado por San Pablo y Río de Janeiro. Las comunicaciones entre cada una de esas regiones eran difíciles y costosas.

La frontera entre Argentina, Brasil y Uruguay comenzó a experimentar un cambio estructural a partir de las obras construidas en la década de los setenta, que contribuyeron a eliminar los obstáculos físicos entre los países. Entre 1960 y 1975 el aumento de la oferta de infraestructura vial y ferrovial y, por consecuencia, de los servicios de transporte, fue producto de la industrialización de ciertas áreas del Cono Sur. En esa época recién se logró conectar estrechamentela región mesopotámica con el resto de Argentina, a través de tres cruces físicos sobre el río Paraná: el túnel que une las ciudades de Santa Fe y Paraná, y los grandes puentes del complejo vial ferroviario Zárate-Brazo Largo (1974) entre Argentina y Uruguay por vía terrestre, de Resistencia a Corrientes, y de Fray Bentos a Puerto Unzué (1975). Casi simultáneamente, la Mesopotamia se vinculó hacia el este a través de las obras de conexión sobre el río Uruguay: la represa de Sal to Grande (1983) y los grandes puentes de Gual eguaychú a Rivera y de Colón a Paysandú (1976). Se finalizaron, por otra parte,

${ }^{1}$ El puente cruzaba el río Uruguay a la altura de Corrientes, y había sido inaugurado en 1947, pero la inexistencia de caminos pavimentados que se conecten con él, no alteraron el aislamiento y su función estuvo limitada a la vinculación de las dos ciudades fronterizas. 
obras que unieron definitivamente a Chile con Mendoza, y se mejoraron las conexiones con Bolivia y Paraguay. Los puentes de la década de los ochenta unieron a Posadas con Encarnación, entre Argentina y Paraguay, Puerto Iguazú con Foz de Iguazú entre Argentina y Brasil, y a esta última ciudad con Ciudad del Este, en Paraguay.

En cuanto al sistema de carreteras en la región, éste se encuentra interconectado básicamente a lo largo de tres ejes: uno norte-sur, que vincula las principales ciudades de la franja oriental (BrasilUruguay-Argentina); otro norte-sur, sobreel Occidente (Chile-Perú); y el tercero, este-oeste, vinculando el centro de Argentina con el centro de Chile, que interconecta los dos ejes anteriores (ver cuadro 1).

En relación con la evolución del sistema ferrovial, se destaca la importancia que tuvo en el crecimiento de nuestro país a partir de la segunda mitad del siglo XIX. En 1857 había apenas 190 km de vías, extensión que pasó a $2516 \mathrm{~km}$ en 1880, y a $16563 \mathrm{~km}$ al finalizar el siglo. Luego siguió la parte central del país desde el Atlántico hasta los A ndes, hacia el nordeste y la Patagonia. Salvo en el caso de los países mediterráneos, los ferrocarriles de los países del Cono Sur, con muy pocas excepciones, no fueron tendidos pensando en su interconexión o en el comercio con los países vecinos. A su vez, el deterioro del servicio ferroviario en toda la región produjo la derivación del transporte de productos al tránsito por carretera. Sin embargo, a mediados del decenio de los años noventa, con las políticas de apertura comercial junto al proceso de integración regional, el intercambio por vía férrea se incrementó.

En el Cono Sur, entre otras importantes obras vinculadas con los proyectos del corredor bioceánico, se encuentran la construcción de grandes complejos portuarios así como el reequipamiento de otros ya existentes. Se busca introducir la participación de la iniciativa privada, para así modernizar la infraestructura de servicios tratando de elevar la productividad y la eficiencia empresarial. De igual manera, se transforman los fletes marítimos, en conjunción con nuevas estructuras portuarias e incorporación de nuevas tecnologías para la eficiencia del transporte y la salida de la agroexportación a través de corredores productivos. 
En cuanto al transporte fluvial, el sistema Paraná-Río de la Plata ha sido objeto de mejoras a través del Proyecto de Hidrovía ParanáParaguay, cuyas obras se encuentran en estado avanzado. La activación de la hidrovía tiene relación con obras realizadas y proyectadas sobre la cuenca: puertos profundos brasileños; proyecto de puerto profundo uruguayo en La Paloma o Rocha; otras soluciones como el puerto de Montevideo en combinación con el puente Buenos Aires Colonia; incorporación de otras vías (alto Paraná, Uruguay y afluentes como el Bermejo), y la complementación del sistema fluvial con los sistemas vial y ferrovial (ver cuadro 1). La red fluvial del centro del Cono Sur no está suficientemente desarrollada, y básicamente se limita a servir de corredor de salida de productos paraguayos y de los puertos de Santa Fe y Rosario y sus áreas agrícolas.

Respecto al movimiento portuario en la región de estudio seleccionada, se puede señalar que en cuanto al tráfico de contenedores, sobresale el puerto de Buenos Aires, con un movimiento de 1139 TEU, seguido por el puerto de Santos, en Brasil, con 799 TEU. Estos dos puertos se encuentran muy por encima del resto de los puertos del Atlántico, e incluso de los puertos del Pacífico que tienen menor movimiento de contenedores. Se destaca en primer lugar el puerto de San A ntonio (CEOAL, 2000). En relación con las cargas generales, y considerando las toneladas en movimiento, los puertos brasileños están por encima de los argentinos. Los primeros siete puertos con mayor movimiento de toneladas de cargas son de ese país. En octavo lugar encontramos a un puerto argentino, el deBuenos Aires (ver cuadro 2).

Las características de los cruces de frontera varían según el tipo de límite, así como por el camino deacceso, la altitud y el clima. ${ }^{2}$ Los

${ }^{2}$ Brasil es el mayor socio comercial de Uruguay, lo que le otorga prioridad a las inversiones destinadas a los pasos de frontera. Así, a pesar de la pequeña extensión de la frontera, se encuentran habilitados varios puntos de tránsito aduanero. El problema del gran tránsito de vehículos no se localiza en las fronteras, sino en los puentes de las carreteras uruguayas, debido a las restricciones impuestas por su reducida capacidad de carga. 


\section{CUADRO 1. Sistema detransporteen los países del Mercosur, Bolivia y Chile.}

\section{Sistema carretero}

A rgentina Tiene $57.000 \mathrm{~km}$ pavimentados y 8.000 de tierra y ripio. En cuanto a la red, se destacan la RN 40, que cruza el país de Norte a Sur paralela a la Cordillera de los Andes, y la RN 3, eje patagónico, vincula la Capital Federal con Tierra del Fuego (vía Chile). Hacia el NE y NO, las RN 12 y 11 vinculan con Iguazú y Asunción, y desde Córdoba hacia el noroeste se llega a Tucumán y a La Quiaca. Diversos corredores conectan la costa atlántica con la cordillera: de Comodoro Rivadavia a Esquel, de Bahía Blanca a Neuquén y a Bariloche, de Bahía Blanca a Córdoba y al centro del país, de Capital Federal a Mendoza, por la RN 7. La ruta más corta San Pablo-Buenos Aires es por la RN 13 sobre la frontera Uruguaya cruzando a Brasil por Uruguayana, para luego continuar por la BR290 o BR285.

Brasil $\quad$ Tiene más de $30.000 \mathrm{~km}$ de carreteras federales pavimentadas que necesitan inversiones para su recuperación y conservación. Presenta muy buenas conexiones con la Mesopotamia argentina, pero con Bolivia y Paraguay, presentan deficiencias en comunicaciones viales interiores. La utilización de la Hidrovía Paraná-Paraguay para la producción del Mato Grosso, interconectándose luego del Puerto de Barranqueras, permite acceder a los puertos del Atlántico. Las rutas más importantes son la que une Sao Paulo y por Campo Grande hacia Santa Cruz de la Sierra y al Pacífico y la ruta entre Paranaguá, Curitiba y Foz de Iguazú.

Paraguay Tiene $2.745 \mathrm{~km}$ pavimentados en estado precario. Es limitada en cuanto a sus articulaciones interiores y especialmente en la carretera longitudinal Asunción-Eugenio Garay. La relación con Chile y Bolivia a partir de la infraestructura es débil, a pesar de existir un importante flujo de cargas desde Iquique y a través del Paso de Jama que conecta Argentina con la Región de Antofagasta en Chile.

Uruguay Tiene $8.610 \mathrm{~km}$, de los cuales $2.334 \mathrm{~km}$ están asfaltados. En la red principal, al rededor de 50 puentes tienen restricciones de capacidad. Las cinco carreteras más importantes son la R1, desde Colonia a Montevideo, la R3, desde la R1 sobre el Río de la Plata hacia el Norte, pasando por Paysandú en la frontera con Argentina, Salto y Bella Unión, al Noroeste del País. La R6, de Montevideo hacia el Norte, pasando por Durazno, Tacuarembó y Rivera en la frontera con Brasil, y las R8 y 9, ambas de Montevideo, la primera hacia el norte, por Minas, Treinta y Tres y Melo a la frontera con Brasil, y la segunda, bordeando la costa, por San Carlos y Rocha.

Bolivia Tiene $1.536 \mathrm{~km}$ pavimentados y planea mejorar sus conexiones con Brasil. La carretera en mejores condiciones es la que une La Paz con los Deptos de Cochabamba y Santa Cruz, con deficiencias hacia el Sur y discontinuidades en los trazados especialmente en los Deptos de Chuquisaca, Tarija y Potosí.

Chile

Tiene $11.000 \mathrm{~km}$ pavimentados, concentradas sobre el litoral, pero no soportan grandes flujos. Solamente los cruces internacionales entre Los Andes y Mendoza, y la conexión con Perú, están en condiciones aceptables. La red se articula a partir de la carretera panamericana que cruza longitudinalmente al país, y cruces transversales que van formando una malla de conexión. Con Bolivia se ha relacionado mejor que con Argentina, dado que la geografía de este país favorece la relación y por ello la producción Boliviana llega a los puertos Chilenos. 


\section{Sistema ferrovial}

Argentina $\quad$ Tiene más de $34.000 \mathrm{~km}$ de ferrovías, de trocha media y ancha, de los cuales $20.941 \mathrm{~km}$. fueron concesionados a operadores privados entre 1991 y 1993. La red se repartió entre cinco empresas que explotan los ferrocarriles de cargas. ${ }^{1}$ Sus ramales sirven principalmente al NOA ${ }^{2}$ (FFCC Gral. Belgrano), cruza a Chile por Socompa y empalma con un ramal de Ferronor SA de Chile. Se conecta con los puertos de A ntofagasta e Iquique. En el borde del Río Paraná, el FFCC Mesopotámico Gral. Urquiza SA permite la conexión con Uruguay por la corona de la represa de Salto Grande y a la red de AFE a Montevideo, y con Paraguay por el puente San Roque González Posadas-Encarnación y desde allí hasta Asunción. ${ }^{3}$ Debe agregarse el FFCC Nuevo Central Argentino que llega hasta la ciudad de Tucumán. La única conexión ferroviaria a Brasil se produce en Paso de los Libres-Uruguayana, desde donde se vincula con la Red Ferroviaria Federal SA (RFFSA) a los puertos atlánticos de Porto Alegre y Río Grande, y, mediante un ramal desde Santa María, con San Francisco do Sul, Paranaguá y Santos.

Brasil Tiene $38.300 \mathrm{~km}$. de vías en seis diferentes líneas, gran parte en trocha media. Inició un proceso de concesión en 1995 con la conexión BaurúCorumbá de $1.100 \mathrm{~km}$. Se destaca la concesión de las ferrovías de la región Sudestey región Sur que dan acceso a los principales puertos Brasileños y permiten la interconexión en trocha métrica y media con Argentina, Paraguay y Uruguay.

Paraguay Tiene su sistema ferroviario en estado precario. Existe un Plan de recuperación de 336km de vías férreas entre Ipacaray y Encarnación, para restablecer la conexión de Asunción con Buenos Aires y Montevideo. Propone conectar la represa de Itaipú a Asunción y una línea férrea de Asunción a Guaira, en la frontera con Brasil. Este país aún no ha podido privatizar el sistema ferroviario.

Uruguay Delos aproximadamente $3.000 \mathrm{~km}$ de vías férreas existentes en Uruguay, solamente $2.000 \mathrm{~km}$ están en operación y su funcionamiento es deficiente. En este país no se han privatizado las líneas férreas.

Bolivia Tiene 3.694km de líneas férreas separadas en dos secciones, Andina y oriental, ambas en condiciones precarias y concesionadas a privados. Se conectan sí en Santa Cruz de la Sierra-La Paz. La red oriental creció significativamente, particularmente por la ruta a Brasil por Quijano.

Chile

Tiene $8.870 \mathrm{~km}$ de ferrocarriles con tres trochas diferentes, tiene conexiones con Argentina y Bolivia en trocha métrica. De los países de la subregión, es el que porcentualmente transporta más carga por este modo. En 1995 se privatizaron las líneas férreas.

${ }^{1}$ Ferroexpreso Pampeano, 5.200 km. (Corredor Rosario- Bahía Blanca), .Ferrosur Roca, 3.300 km. (ex línea Roca), BuenosAiresal Pacífico, 5.500km. (ex línea San Martín), N uevo central A rgentino, 5.000km. (ex línea Mitre), Ferrocarril Mesopotámico, 3.000km. (ex línea Urquiza).

${ }^{2}$ Los ramales del Ferrocarril Belgrano (no privatizado) se conectan con la red Boliviana dela Empresa Nacional deFerrocarriles (ENFE) a través de los pasos deLa Quiaca-Villazón con Oruro y La Paz, y un ramal hasta el puerto Chileno deA rica, y, más al Este, en el paso deSalvador Mazza y Yacuiba, a Santa Cruz dela Sierra, y desdeallí hasta Puerto Suárez, y el Puerto de Santosen Sao Paulo.

${ }^{3}$ La operación del ferrocarril Paraguayo es dificultosa por el tipo de tracción y estado de la infraestructura. Por esta razón se construyó una estación de transferencia en territorio Paraguayo, cerca del puenteinternacional mencionado. 


\section{Sistema marítimo y fluvial}

Argentina El corredor fluvial de la Hidrovía, donde profundidad hasta Santa Fe ha sido llevada a 32 pies, concentra puertos destacados, como los de Rosario, Santa Fe y Barranqueras, que permiten combinaciones con corredores viales interoceánicos y ferroviarios. Hasta A sunción se ha realizado la licitación para continuar las obras. En relación al transporte marítimo, a lo largo de la costa atlántica se localizan puertos de distinta envergadura, destacándose Buenos Aires y Bahía Blanca, que han sido objeto de mejoras.

Brasil

Se destacan los Puertos de Santos y Paranaguá, que han sido objeto de mejoras, y en Santa Catarina, 4 importantes puertos marítimos, para el transporte de larga distancia de graneles y carga general, y con posibilidad de operar contenedores: Sao Francisco do Sul (6to a nivel nacional), Itajaí (4to en movimiento de contenedores), Laguna e Imbituba. ${ }^{4}$

Paraguay Se apunta a la inversión privada en el sector. Las Hidrovías que cruzan su territorio representan alternativas de interconexión y facilitación para el intermodalismo.

Uruguay Tiene por objetivos jerarquizar sus puertos, convertir al Puerto de Nueva Palmira en punto final de la Hidrovía, y modernizar el puerto de Montevideo, a través de inversiones en las terminales portuarias.

Bolivia Los puertos de Bolivia hidroviarios sobre el río Paraguay (Suárez, Aguirre y Busch) están recibiendo inversiones privadas y aumentando su volumen de operaciones. Se está considerando prioritariamente el acceso a los puertos.

Chile $\quad$ Chile impulsa un amplio Plan de modernización portuaria. Los niveles de ocupación de los puertos de la zona central, donde están ubicados Valparaíso y San Antonio, son muy elevados provocando dificultades. La mayoría muestran deficiencias en los servicios complementarios.

${ }^{4}$ Este último es el único puerto privado del país. 


\section{CUADRO 2. Puertosterminales detransferencia destacados en el Cono Sur para la Red deTransporteSubregional}

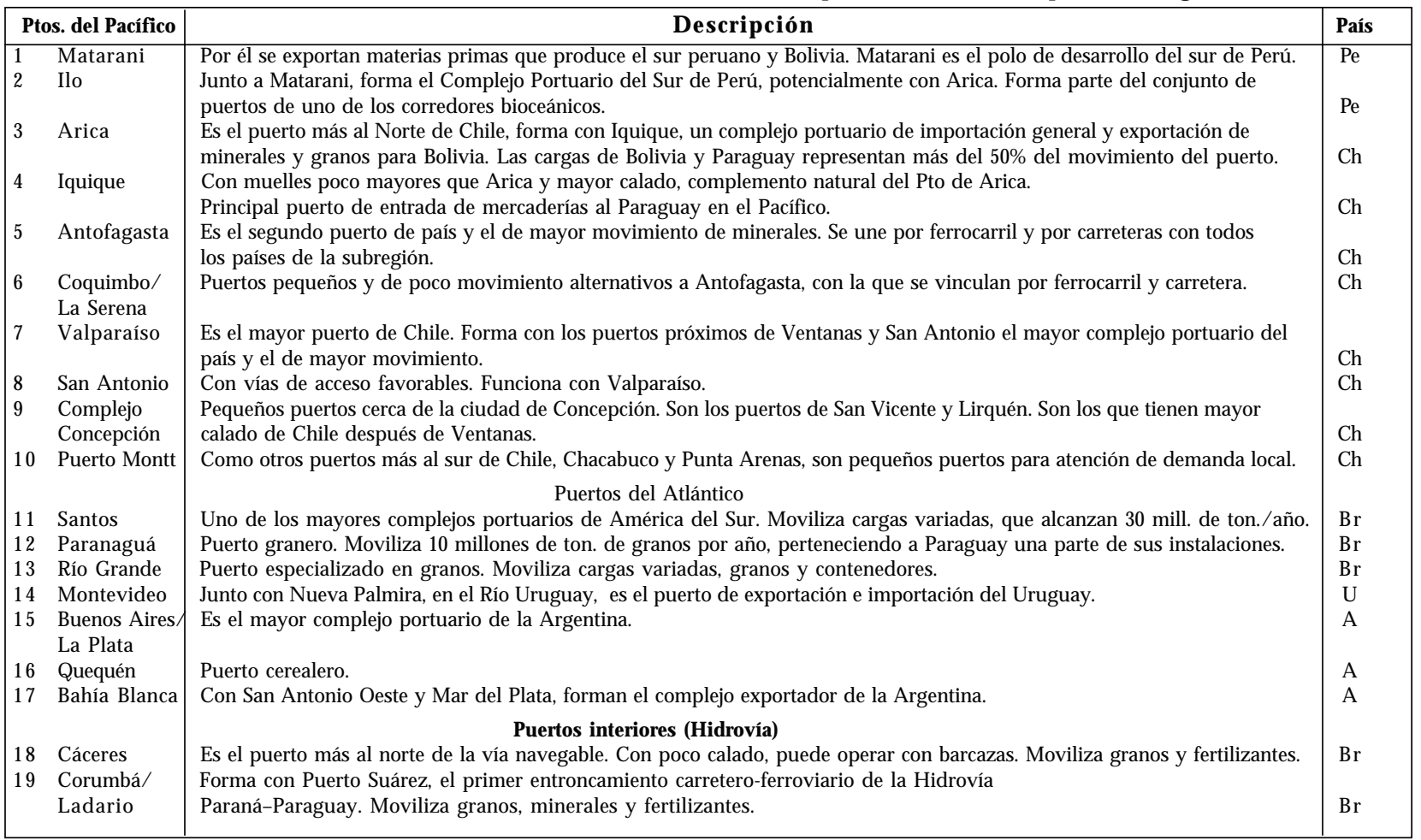


20 Pto Suarez/ Principal puerto exportador de granos de Bolivia. En este complejo portuario se establece la conexión de la red este Pto Aguirre de los ferrocarriles Bolivianos con la Hidrovía.

21 Pto Esperanza Puerto en la región productora de soja de Brasil, localizado a $2.630 \mathrm{~km}$. de Buenos Aires.

22 Puerto Busch Único puerto Boliviano ubicado en el Río Paraguay. Tiene problemas con el acceso carretero no pavimentado de más de 200 km y no está enlazado con el ferrocarril.

23 Guaíra $\quad$ A $2.100 \mathrm{~km}$ de Buenos Aires, por el Río Paraná. Es un punto importante de la Hidrovía Paraná-Tietê.

24 Asunción Es el principal entroncamiento carretero-ferroviario de Paraguay.

25 Encarnación / Los dos puertos están enlazados a Buenos Aires (son 1.583km.)

Posadas

26 Formosa

27 Resistencia/

Corrientes.

Es la conexión carretera-ferroviaria con la Hidrovía más al norte de la Argentina. El FFCC Belgrano enlaza Formosa a Embarcación, pero en condiciones precarias.

Barranqueras

28 Santa $\mathrm{Fe} /$

Paraná

29 Ibicuy

30 Rosario

En el km.1.198 de la Hidrovía. Se entronca por carretera y ferrocarril hacia el norte y Rosario. La ciudad de Corrientes es un punto importante para la integración modal.

Es la intersección con la única carretera totalmente pavimentada que liga el Atlántico con el Pacífico, y está en el km. 590 de la Hidrovía. Una autopista permite el enlace con el Puerto de Rosario.

Cierra la Hidrovía en el Sur, y parte de las estrategias para transformar el funcionamiento de las operaciones portuarias.

A $420 \mathrm{~km}$. de Buenos Aires por el Río Paraná, junto a otros próximos representa los puntos interiores de la Hidrovía que

permiten la operación de navíos oceánicos. Granelero. Ligado a Buenos Aires, a 300km. por autopista que será

complementada con el tramo Rosario-Córdoba.

31 Concepción Último puerto con posibilidades de operar con salida al Río de la Plata. Con proyecto de aumento del calado. Forma parte del Uruguay

del corredor de exportación central, con accesibilidad ferroviaria y perspectiva de intermodalidad.

Puede complementarse funcionalmente con el Puerto de lbicuy.

32 Campana En el km. 97 de la Hidrovía, punto de navegación inicial del canal Emilio Mitre, en el lado argentino del Río de la Plata, y primer puerto interior de la Argentina.

33 Nva. Palmira/ Puertos con características de marítimos, localizados en la desembocadura del Río Uruguay, utilizan el canal de navegaColonia ción Martín García, en el Río de la Plata.

FUENTE: Elaboración propia.

A: Argentina, Br: Brasil, P: Paraguay, U: Uruguay, Bo: Bolivia, Ch: Chile, Pe: Perú 
cruces de cargas en la actual idad se concentran en donde la infraestructura, antes del proceso en marcha, ya estaba en mejores condiciones para el tránsito, y en donde en esta etapa se siguen concentrando los proyectos. Existe un solo corredor carretero totalmente asfal tado entre Argentina y Chile (con cruce por el sistema del Cristo Redentor), y solamente una alternativa ferroviaria por frontera entre Brasil y Argentina (Uruguayana-Paso de los Libres) y entre Argentina y Chile (por Socompa).

El tránsito del comercio interregional se concentra en dos pasos entre Argentina y Brasil: en Paso de los Libres-Uruguayana, con $23.7 \%$ de las exportaciones y $39 \%$ de las importaciones argentinas, y Foz do Iguaçú-Puerto Iguazú, por donde pasan $21.5 \%$ y $8.1 \%$ respectivamente. El tercer paso es el de Cristo Redentor, entre Argentina y Chile, seguido del paso brasileño-paraguayo de Ciudad del Este-Foz do Iguaçú, y los de la Argentina con Paraguay y Uruguay (cuadro 3).

La participación de los distintos modos en el comercio exterior total de los países del Mercosur muestra la preponderancia del modo marítimo, inclusive para los intercambios intrarregionales, desde comienzos de la vigencia del Mercado Común. Este modo transporta más de $20 \%$ de cargas totales de cada uno de los países de la región, representando más de $80 \%$ en el caso de Argentina y Brasil. En el caso del comercio intrarregional por vía fluvial, si bien los val ores son menores, en Brasil siguen siendo de más de $80 \%$, y $70 \%$ en Uruguay. Las carreteras le siguen en proporción, mientras que el modo ferroviario está poco desarrollado, aunque las tendencias muestran su recuperación ${ }^{3}$ (cuadro 4).

En el caso de Brasil, Paraguay y Bolivia, no sólo se incrementaron los volúmenes de exportación, sino también los valores. El impacto de la expansión de las exportaciones no ha sido igual para cada

${ }^{3}$ Las únicas conexiones ferroviarias en operación se encuentran en Paso de Los Libres-Uruguayana, Rivera-Sant'Ána do Livramento, Posadas-Encarnación, Concordia-Salto y Colón Paysandú. En los dos primeros casos, la diferencia de trochas obliga a realizar transferencia de cargas. 
modo de transporte, sino que ha variado dependiendo del país destino de las mismas. El $85 \%$ de las exportaciones a Brasil parten en buque, y casi $14 \%$ en camión; este último modo es el que más se ha expandido en relación con el crecimiento de los otros modos. En el caso de Chile, 70\% del volumen exportado se transporta por ductos, y el resto se distribuye en similares proporciones entre el transporte marítimo y carretero; de estos dos modos, el camión es el que tiende a aumentar con mayor velocidad. La participación del ferrocarril es muy baja pero con tendencia al incremento.

Los intercambios con Chile y Bolivia son un claro ejemplo de las asimetrías en la asignación por modos, ya que la menor participación del transporte marítimo o fluvial no ha promovido el desarrollo del modo ferroviario como alternativa natural por el menor costo respecto al autotransporte.

En los países del Cono Sur, Chile ha sido el pionero en el proceso de privatización de empresas públicas (1985), seguido por Argentina (1990), Brasil y Perú (1991), y más recientemente, por Bolivia, Uruguay y, finalmente, Paraguay.

La experiencia del Cono Sur muestra que la demanda de inversiones y el impacto del sector privado en el sector transporte varían de acuerdo con los distintos subsectores. La productividad de los puertos y ferrocarriles en Argentina y Chile - que han sido parcialmente privatizados- aumentó notablemente sin inversiones significativas. En cambio, la red de carreteras requiere de fuertes inversiones inmediatas, tanto para remediar el deterioro como para tender e interconectar los sistemas viales existentes. La experiencia de Brasil y Chile en la contratación de empresas privadas para el mantenimiento de carreteras ha sido exitosa, no tanto así en el caso de Argentina y otros países, donde han surgido algunas dificultades de diversa índole.

Las empresas ferroviarias de Argentina, Bolivia, Brasil y Chile se encuentran en su mayoría privatizadas, quedando exclusivamente a cargo del transporte de cargas, con destino a puertos atlánticos o pacíficos. Uruguay y Paraguay no han privatizado sus ferrocarriles. 


\section{CUADRO 3. Pasos fronterizos existentes en el Cono Sur.}

\begin{tabular}{|c|c|c|c|c|c|}
\hline \multicolumn{3}{|c|}{ Países } & Paso & & Características \\
\hline 1 & A & Bo & La Quiaca-Villazón & $\mathrm{C}-\mathrm{F}$ & $\begin{array}{l}\text { Liga Oruro y La Paz con Argentina, y la parte oeste de la conexión ferroviaria con la línea férrea } \\
\text { argentina. En ambos territorios son deficientes los ferrocarriles. La carretera argentina tiene } \\
\text { planes de pavimentación hasta la frontera. }\end{array}$ \\
\hline 2 & A & Bo & $\begin{array}{l}\text { Pocitos-Yacuiba o Salvador } \\
\text { Mazza-Yacuiba }\end{array}$ & $\mathrm{C}-\mathrm{F}$ & $\begin{array}{l}\text { Originalmente sólo ferroviario, une la línea férrea argenti na con la boliviana hasta Santa Cruz } \\
\text { de la Sierra y al Brasil. Argentina tiene la carretera pavimentada hasta la frontera. Es uno de los } \\
\text { caminos de exportación del norte argentino. }\end{array}$ \\
\hline 3 & A & Bo & Aguas Blancas-Pozo Bermejo & PC & $\begin{array}{l}\text { Con puente carretero internacional sobre el Río Bermejo. Tiene movimiento local pequeño, } \\
\text { mayor en la margen Boliviana. }\end{array}$ \\
\hline 4 & A & $\mathrm{Br}$ & Paso de los Libres-Uruguayana & PC-F & $\begin{array}{l}\text { Sobre el Río Uruguay es el principal punto de frontera en intercambios comerciales (cerca del } 80 \% \\
\text { de los intercambios entre los dos países), y el único cruce ferroviario. Tiene un movimiento de } \\
\text { más de } 2.000 \text { camiones por día. }\end{array}$ \\
\hline 5 & A & $\mathrm{Br}$ & Santo ToméSao Borja & PC & $\begin{array}{l}\text { Recientemente concluido, con conexiones carreteras pavimentadas. Existe ferrocarril } \\
\text { del lado argentino, en Brasil, fue erradicada en un tramo de } 150 \mathrm{~km} \text {. la línea férrea. }\end{array}$ \\
\hline 6 & A & $\mathrm{Br}$ & Alvear-Itaquí & $\mathrm{Fb}$ & $\begin{array}{l}\text { De importancia local, para la producción de arroz, con iniciativa privada la construcción de un } \\
\text { puente. Accesos pavimentados carreteros. }\end{array}$ \\
\hline 7 & A & $\mathrm{Br}$ & San Javier-Porto Xavier & $\mathrm{B} \mathrm{Fb}$ & $\begin{array}{l}\text { De carácter secundario y de importancia local. Las autoridades vecinas tienen interés } \\
\text { en construir un puente internacional vial. }\end{array}$ \\
\hline 8 & A & $\mathrm{Br}$ & Alba Posse-Porto Mauá & $\mathrm{Fb}$ & $\begin{array}{l}\text { Con intereses por la construcción de un puente. La travesía es mayor en pasajeros que en } \\
\text { carga. Atiende intereses fronterizos. }\end{array}$ \\
\hline 9 & A & $\mathrm{Br}$ & Com. A. Guacurari-Capanema & $\mathrm{PC}$ & $\begin{array}{l}\text { El puente se construyó por iniciativa del gobierno de Paraná, Brasil, y fue inaugurado } \\
\text { en 1996. Está desviando parte del tráfico de Foz. }\end{array}$ \\
\hline 10 & A & $\mathrm{Br}$ & B de Irigoyen-Dionisio Cerqueira & $\mathrm{C}$ & Pasajeseco por instalaciones aduaneras para atender al tráfico local. N o presenta gran movimiento. \\
\hline 11 & A & $\mathrm{Br}$ & Comandante Rosales-Paraíso & PC & $\begin{array}{l}\text { Por iniciativa de las autoridades locales, se construyó el puente sobre el río Pepirí Guazú, para } \\
\text { atender tráficos locales. Funciona desde 1994, con restricciones para vehículos pesados. }\end{array}$ \\
\hline 12 & A & $\mathrm{Br}$ & Puerto Iguazú-Foz do Iguaçú & PC & $\begin{array}{l}\text { El Puente Tancredo Neves fue inaugurado en 1985, absorbe menos del } 20 \% \text { del movimiento de } \\
\text { cargas entre Argentina y Brasil. }\end{array}$ \\
\hline 13 & A & $\mathrm{Br}$ & Pasos secundarios & $\mathrm{L}$ & $\begin{array}{l}\text { Tránsito de personas de localidades próximas. Puerto San Isidro-Porto Santo Izidro y San Javier- } \\
\text { Porto Lucena. }\end{array}$ \\
\hline
\end{tabular}




\begin{tabular}{|c|c|c|c|c|c|}
\hline 14 & A & $\mathrm{Ch}^{5}$ & Jama* & C & $\begin{array}{l}\text { El proyecto prevé la pavimentación y conservación de la carretera de } 150 \mathrm{~km} \text {. entre San Pedro de } \\
\text { Atacama y el paso de Jama, a } 4.230 \mathrm{~m} \text { de altitud. Los accesos al paso presentan } 195 \mathrm{~km} \text {. de } \\
\text { caminos a altitudes superiores a } 4.000 \mathrm{~m} \text { en territorio Chileno. }\end{array}$ \\
\hline 15 & $A$ & $\mathrm{Ch}$ & Sico* & C & $\begin{array}{l}\text { Cerca de Jama. En Argentina, el trazado es sinuoso, por altitudes de más de } 4.500 \mathrm{~m} \text {. El paso está } \\
\text { a } 4.020 \mathrm{~m} \text {. En territorio Chileno son } 174 \mathrm{~km} \text {. por encima de los } 4.000 \mathrm{~m} \text { con interrupciones por } \\
\text { motivos climáticos. Cruzan vehículos pesados principalmente transportando minerales. }\end{array}$ \\
\hline 16 & $A$ & $\mathrm{Ch}$ & San Francisco * & C & $\begin{array}{l}\text { El paso está a } 4.726 \mathrm{~m} \text {, con un promedio de cruce de un vehículo de pasajeros por día, sin registrar } \\
\text { cruces de cargas. Tiene más de } 200 \mathrm{~km} \text { a más de } 4.000 \mathrm{~m} \text { de altura en Chile, con una la altura } \\
\text { máxima de } 4.747 \mathrm{~m} \text {. }\end{array}$ \\
\hline 17 & $A$ & $\mathrm{Ch}$ & Agua Negra* & C & $\begin{array}{l}\text { Es el paso de mayor altitud, a } 4.765 \mathrm{~m} \text {, con grandes extensiones por encima de los } 4.000 \mathrm{~m} \text {. Se hacen } \\
\text { tareas de mantenimiento del camino. }\end{array}$ \\
\hline 18 & $A$ & $\mathrm{Ch}$ & Sistema del Cristo Redentor * & $\mathrm{C}$ & $\begin{array}{l}\text { A 3.185m de altitud, es el más importante entre los dos países (cerca del } 70 \% \text { del movimiento de } \\
\text { carga terrestre). El pasaje ferroviario está obstruido por derrumbes desde } 1985 \text { y el túnel ferro- } \\
\text { viario fue adaptado en } 1995 \text { para cargas peligrosas. La carretera asfaltada tiene un trecho } \\
\text { sinuoso (Los caracoles). Debido a las condiciones climáticas, el paso queda interrumpido } 60 \text { días } \\
\text { por año, argumento quesustenta el proyecto deconstrucción deun túnel a baja altura, atravesando } \\
\text { la Cordillera de los Andes. }\end{array}$ \\
\hline 19 & $A$ & $\mathrm{Ch}$ & Pehuenche* & C & $\begin{array}{l}\text { Está a } 2.553 \mathrm{~m} \text {, alternativa al Cristo Redentor cuando está interrumpido. También sufre interrup- } \\
\text { ciones por motivos climáticos. Falta la pavimentación de las vías de acceso. }\end{array}$ \\
\hline 20 & $A$ & $\mathrm{Ch}$ & Pino Hachado * & $\mathrm{C}$ & $\begin{array}{l}\text { A } 1.884 m \text {, con vías empedradas, de poco movimiento, también es considerado alternativa al } \\
\text { Cristo Redentor cuando éste se interrumpe. }\end{array}$ \\
\hline 21 & A & $\mathrm{Ch}$ & Cardenal Samoré Puyehue* & C & $\begin{array}{l}\text { Segundo punto de frontera en importancia, a } 1.308 \mathrm{~m} \text {, con el } 25 \% \text { de movimiento de vehículos } \\
\text { del Cristo Redentor, y } 10 \% \text { de cargas de ese cruce. Es el principal paso usado cuando se inte- } \\
\text { rrumpe el del Cristo Redentor. }\end{array}$ \\
\hline 22 & A & $\mathrm{Ch}$ & Coihaique* & C & $\begin{array}{l}\text { Camino empedrado con cruce a } 795 \mathrm{~m} \text { de altitud. Con pequeño movimiento para los dos } \\
\text { países, sólo de su área de influencia. }\end{array}$ \\
\hline 23 & A & $\mathrm{Ch}$ & Huemules* & C & Camino empedrado a 502m. Sólo con movimiento local y tránsito de personas. \\
\hline
\end{tabular}

${ }^{5}$ En julio de 1992 fue creado El Grupo Técnico Mixto, que elaboró un Plan Maestro General de Pasos Fronterizos, estableciendo 12 pasajes preferenciales, sobre los cuales acordaron acciones para el mejoramiento. 


\begin{tabular}{|c|c|c|c|c|c|}
\hline 24 & A & $\mathrm{Ch}$ & Integr. Austral Monte Aymond * & C & $\begin{array}{l}\text { Altitud de } 150 \mathrm{~m} \text {. Y relativamente gran movimiento por sus caminos empedrados, llegando a } \\
\text { más de } 200.000 \text { toneladas por año. }\end{array}$ \\
\hline 25 & A & $\mathrm{Ch}$ & San Sebastián * & C & $\begin{array}{l}\text { En la Isla Grande de Tierra del Fuego. Camino empedrado a 296m. es el paso obligado desde } \\
\text { territorio argentino para alcanzar la zona continental cruzando el Estrecho de Magallanes } \\
\text { por el lado Chileno en la Primera Angostura. }\end{array}$ \\
\hline 26 & A & $\mathrm{Ch}$ & Guaitiquina & C & $\begin{array}{l}\text { A } 4.295 \mathrm{~m} \text { de altitud, próximo a Jama y Sico, está incluido en el Acuerdo Panamericano de } \\
\text { Carreteras. }\end{array}$ \\
\hline 27 & A & $\mathrm{Ch}$ & Socompa & $\mathrm{F}$ & $\begin{array}{l}\text { A la altura de Antofagasta, a } 3.856 \mathrm{~m} \text { de altitud, es la conexión ferroviaria existente con } \\
\text { Argentina, parte sur de Bolivia y Brasil , en trocha métrica, y conforma la única conexión } \\
\text { ferroviaria completa en una sola trocha del Atlántico al Paćfico. }\end{array}$ \\
\hline 28 & A & $\mathrm{Ch}$ & Pichachén & C & $\begin{array}{l}\text { Paso secundario abajo del Sistema de Cristo Redentor, con caminos de tierra, a } 2.062 \mathrm{~m} \text { de } \\
\text { altitud. }\end{array}$ \\
\hline 29 & A & $\mathrm{Ch}$ & Iclama & C & $\begin{array}{l}\text { Camino empedrado a } 1.298 \mathrm{~m} \text { de altitud, con bajo movimiento de pasajeros, y casi ninguna } \\
\text { carga. }\end{array}$ \\
\hline 30 & A & $\mathrm{Ch}$ & Mamuil Malal & C & Camino empedrado para tránsito de pasajeros a $1.207 \mathrm{~m}$ de altitud. \\
\hline 31 & A & $\mathrm{Ch}$ & Huahum & C & A $659 \mathrm{~m}$ de altitud, empedrado. \\
\hline 32 & A & $\mathrm{Ch}$ & Pérez Rosales & C & Camino empedrado para pasajeros a $1.022 \mathrm{~m}$ de altitud. \\
\hline 33 & A & $\mathrm{Ch}$ & Futaleufú & C & Empedrado a 515m, con puesto de frontera, registra un movi. medio de 100 pasajeros por día. \\
\hline 34 & A & $\mathrm{Ch}$ & Río Jeinemi & C & Camino empedrado para pasajeros a $231 \mathrm{~m}$. de altura. \\
\hline 35 & A & $\mathrm{Ch}$ & Dorotea & C & Empedrado, a $761 \mathrm{~m}$ de altura, con movimiento de 10 vehículos por día. \\
\hline 36 & A & $\mathrm{Ch}$ & Casas Viejas & C & Camino empedrado para pasajeros a $1.022 \mathrm{~m}$. de altura. \\
\hline 37 & A & $\mathrm{Ch}$ & $\begin{array}{l}\text { Pasajes secundarios de Tránsito } \\
\text { Vecinal Fronterizo }\end{array}$ & C & $\begin{array}{l}\text { Las condiciones físicas de todos estos pasajes los hacen casi intransitables, son usados para } \\
\text { para tránsito local, travesía de caprinos, turismo y actividades deportivas. Son, de Norte a Sur } \\
\text { Sur: Tres Quebradas o Toro Muerto, Bañitos, La Gloria o La Quebrada Colorada, Doña Rosa, } \\
\text { Las Lágrimas, Planchón, Potrerillo, Desecho, Copahue, Bariloche o Monte Tronador y Río Manso. } \\
\text { Principal pasaje de frontera entre los dos países. Es el Puente San Ignacio de Loyola. }\end{array}$ \\
\hline 39 & A & $P$ & Encarnación-Posadas & PC-F & $\begin{array}{l}\text { Construido en 1989, única conexión ferroviaria de Paraguay con el exterior, para transportar } \\
\text { granos de la parte oriental del Paraguay. }\end{array}$ \\
\hline 40 & A & $P$ & Misión La Paz-Pozo Hondo & PC & $\begin{array}{l}\text { Travesía local, prevista en las notas internacionales como componente de un Corredor } \\
\text { Bioceánico carretero. }\end{array}$ \\
\hline
\end{tabular}




\begin{tabular}{|c|c|c|c|c|c|}
\hline 41 & A & $\mathrm{U}$ & Buenos Aires-Colonia & $\mathrm{Fb} \mathrm{Ba}$ & $\begin{array}{l}\text { Presenta un intenso movimiento y cuenta con estudios para la construcción de un puente que } \\
\text { compone el corredor Sao Paulo-Buenos Aires. }\end{array}$ \\
\hline 42 & A & U & Gualeguaychú-Fray Bentos & PC & $\begin{array}{l}\text { Pasaje de la ruta más corta Montevideo-Buenos Aires. El puente Lib.San Martín no impone } \\
\text { limitaciones de capacidad. Hay un ferrocarril en igual trocha en las dos ciudades, sin } \\
\text { conexión. Representa el } 80 \% \text { de los intercambios comerciales de Uruguay con Argentina. }\end{array}$ \\
\hline 43 & A & $\mathrm{u}$ & Colón-Paysandú & PC & $\begin{array}{l}\text { El Puente Internacional General Artigas puede ser parte de la ruta más importante de conexión } \\
\text { carretera entre Sao Paulo y Buenos Aires. }\end{array}$ \\
\hline 44 & $A$ & U & Concordia-Salto & PC-F & $\begin{array}{l}\text { El Puente sobre la corona de la represa, es el más al norte entre Argentina y Uruguay. Pequeño } \\
\text { volumen de mercaderías en tránsito. }\end{array}$ \\
\hline 45 & Bo & B & Puerto Suárez-Corumbá & PC-F & Principal puesto de frontera Bolivia-Brasil, no presenta movimiento que dificulte las operaciones. \\
\hline 46 & Bo & $\mathrm{Br}$ & San Matías-Sao Matías & C & $\begin{array}{l}\text { De poco movimiento por la falta de infraestructura viaria de conexión. Es un punto importante } \\
\text { en el corredor de exportación bioceánico. }\end{array}$ \\
\hline 47 & Bo & $\mathrm{Br}$ & Guayará Mirim-Gaujará Mirim & $\mathrm{B} \mathrm{Fb}$ & Llegan carreteras poco transitables en el interior de Bolivia. \\
\hline 48 & Bo & $\mathrm{Ch}$ & Visviri-Charaña & C-F & $\begin{array}{l}\text { Con varios tramos sobre los } 4.000 \text { m de altitud, es el segundo pasaje de importancia entre los } \\
\text { dos países por permitir la conexión ferroviaria de Bolivia con el Puerto de Arica para la } \\
\text { exportación de minerales. Las curvas de pequeño radio, dificultan el flujo de vehículos. }\end{array}$ \\
\hline 49 & Bo & $\mathrm{Ch}$ & Tambo Quemado & C & $\begin{array}{l}\text { Pasa cerca del } 80 \% \text { de las cargas terrestres entre los dos países. A } 4.678 \mathrm{~m} \text { de altitud y cerca de } \\
150 \mathrm{~km} \text {. en cada país a esta altura, presenta dificultades por irregularidades del camino, } \\
\text { radios de curva y pendientes del lado Chileno y la falta de pavimentación y Boliviano. }\end{array}$ \\
\hline 50 & Bo & $\mathrm{Ch}$ & Pisiga & C & $\begin{array}{l}\text { Vincula el puerto de lquique con Bolivia, tiene del lado Chileno más de } 130 \mathrm{~km} \text {. de vías de } \\
\text { tierra consolidar y pendientes escarpadas con } 77 \mathrm{~km} \text {. por encima de los } 4.000 \mathrm{~m} \text { de altitud, y } \\
\text { una máxima de } 4.280 \mathrm{~m} \text {. En la parte Boliviana, a pesar de tener un tramo implementado, cerca } \\
\text { de 30km. próximos a la frontera son un camino simple a consolidar. Movimiento de pasajeros } \\
\text { y carga inferiores a los otros dos pasos. }\end{array}$ \\
\hline 51 & Bo & $\mathrm{Ch}$ & Ollagüe & C-F & $\begin{array}{l}\text { Con dificultades de acceso y tránsito, y por ello poco movimiento. Los accesos carreteros están } \\
\text { sobre los } 4.000 \mathrm{~m} \text { de altitud y con problemas dimáticos. La línea férrea no presenta buenas } \\
\text { condiciones de tránsito. La parte Boliviana, presenta zonas anegadizas. }\end{array}$ \\
\hline 52 & Bo & $\mathrm{Ch}$ & Japú, C.Cancosa, Port. del Cajón & C & Pasajes de tránsito vecinal fronterizo, todos por encima de los 4.400 metros de altitud. \\
\hline 53 & Bo & $\mathrm{P}$ & Coronel Eugenio A. Garay & C & $\begin{array}{l}\text { Unico paso de frontera entre los dos países, refleja la baja intensidad del comercio. Grandes } \\
\text { extensiones sin pavimento en ambos lados. }\end{array}$ \\
\hline
\end{tabular}




\begin{tabular}{|c|c|c|c|c|c|}
\hline 54 & $\mathrm{Br}$ & $\mathrm{P}$ & Ciudad del Este-Foz do Iguaçú. & PC & $\begin{array}{l}\text { Principal conexión entre ambos países y parte de la ruta de exportación por el Puerto de } \\
\text { Paranaguá, donde Paraguay tiene una terminal granera. Está saturado en función al gran }\end{array}$ \\
\hline 55 & $\mathrm{Br}$ & $P$ & P. Juan Caballero-Ponta Porá & C & $\begin{array}{l}\text { Frontera seca de poco movimiento por las condiciones de las carreteras del lado Paraguayo. } \\
\text { Tiende a ser un pasaje de importancia local. }\end{array}$ \\
\hline 56 & $\mathrm{Br}$ & $\mathrm{P}$ & Guaíra-Guaira & $\mathrm{Fb} \mathrm{Ba}$ & $\begin{array}{l}\text { Con movimiento predominantemente turístico. Las carreteras Paraguayas necesitan } \\
\text { pavimentación. }\end{array}$ \\
\hline 57 & $\mathrm{Br}$ & U & Chuy-Chuí & C & $\begin{array}{l}\text { Principal paso carretero entre los dos países. En Brasil la carretera de acceso atraviesa un } \\
\text { área de equilibrio ecológico inestable, lo que dificulta el aumento de capacidad. En Uruguay, } \\
\text { puentes estrechos y de capacidad reducida, dificultan el aumento del tráfico. }\end{array}$ \\
\hline 58 & $\mathrm{Br}$ & $\mathrm{U}$ & Rio Branco-Jaguarao & PC-F & $\begin{array}{l}\text { Segundo volumen de tránsito entre ambos países. Capacidad saturada principalmente por las } \\
\text { vías de acceso precarias en Uruguay, y situarse en una región anegadiza. La línea férrea del } \\
\text { lado Brasileño, además de haber sido erradicada hasta Pelotas, tenía trocha métrica, diferen- } \\
\text { te a la de Uruguay, de } 1,435 \mathrm{~m} \text {. Periódicamente, pasan por el puente algunos vagones con arroz } \\
\text { de Uruguay a Brasil, donde la carga se traslada a grandes camiones que no tienen condiciones } \\
\text { para transitar en el interior del Uruguay. }\end{array}$ \\
\hline 59 & $\mathrm{Br}$ & $\mathrm{U}$ & Rivera-Sant'A na do Livramento & C-F & $\begin{array}{l}\text { Frontera seca. Presenta movimientos inferiores a los de los otros pasos, en virtud de las difi- } \\
\text { cultades de circulación de camiones. Estado deficiente de la línea férrea que en esa zona está } \\
\text { prácticamente desactivada en ambas márgenes. }\end{array}$ \\
\hline 60 & $\mathrm{Br}$ & U & Artigas-Quaraí & PC & $\begin{array}{l}\text { Con poco movimiento. En Uruguay el ramal ferroviario está desactivado y las carreteras se } \\
\text { encuentran en estado muy deficiente. }\end{array}$ \\
\hline 61 & $\mathrm{Br}$ & U & Bella Unión-Barra do Quaraí & C & $\begin{array}{l}\text { Punto extremo de Uruguay. El ramal ferroviario está desactivado, pero podría servir de } \\
\text { complementación del paso de frontera. }\end{array}$ \\
\hline 62 & $\mathrm{Br}$ & U & Aceguá & C & $\begin{array}{l}\text { Paso de travesía de interés local no habilitado en forma permanente, con movimiento en } \\
\text { épocas de cosechas. }\end{array}$ \\
\hline
\end{tabular}

FUENTE: Elaboración propia.

A: Argentina, Br: Brasil, P: Paraguay, U: Uruguay, Bo: Bolivia, Ch: Chile, Pe: Perú.

* Preferenciado por el GTM.

C: Carretero, F: Ferroviario, P: Pente, Fb: ferry-Boat, B: Balsas, Ba: Barcos, L: Lanchas. 
El área de frontera argentino-brasileña, junto a la argentino-uruguaya, sobre el río Uruguay, concentra buena parte de la infraestructura de transporte con la que cuenta el proceso integrador. Las favorables condiciones del terreno (superficies sin serios impedimentos físicos, excepto los ríos, que se salvan con puentes carreteros en varios puntos de conexión) permiten que estas zonas fronterizas constituyan lugares de paso obligados de comunicación entre enormes mercados productivos. Es el caso de los pasos fronterizos del centro y sur deEntre Ríos, que permiten el fluir de bienes y personas entre el área centro-sur de Brasil (San Pablo y Porto Alegre, con sus respectivas zonas de influencia) y la región centro-litoral argentina, y también de las provincias de Corrientes y Misiones, que se disputan, a través de diversos proyectos, el incremento del flujo que se irá experimentando en el marco de la integración, pretendiendo formar parte del corredor del Mercosur (cuadro 5).

DIAGNÓSTICO DE LA SITUACIÓN ACTUAL DEL SISTEMA DE TRANSPORTE

A través de la información expuesta sobre la situación del sistema de transporte en el Cono Sur, y en relación con las nuevas demandas para el transporte de cargas, se pueden observar distintas situaciones:

I. La infraestructura de transporte fue construida a partir de una base de defensa y protección del territorio nacional de cada país, y volcada hacia una economía interna protegida por la sustitución de importaciones, que resulta inadecuada para las actuales necesidades de intercambio.

II. Por ello, las carreteras no siempre permiten conexiones directas, y varios tramos necesitan mejoras o mantenimientos compatibles con las necesidades actuales.

III. Esta inadecuación no sólo se verifica en el trazado, sino también en la capacidad para recibir grandes volúmenes de cargas. Por ejemplo, los puentes en Uruguay no tienen capacidad y se convierten en un obstáculo. 
CUADRO 4. Porcentajedelosflujosdemercanáasdesdey hacialaArgentinasegúnmododetransporte, 1997.

\begin{tabular}{|l|c|c|c|c|c|c|}
\hline \multirow{2}{*}{ País } & \multicolumn{3}{|c|}{ Exportaciones } & \multicolumn{3}{c|}{ Importaciones } \\
\cline { 2 - 7 } & Fluvial-Marítimo & Ferroviario & Carretero & Fluvial-Marítimo & Ferroviario & Carretero \\
\hline Brasil & 82,43 & 2,32 & 15,23 & 85,85 & 0,46 & 13,67 \\
Bolivia & 0,00 & 2,40 & 97,95 & 0,01 & 8,30 & 91,50 \\
Chile & 10,02 & 0,00 & 89,97 & 49,51 & 1,77 & 48,70 \\
Paraguay & 12,75 & 0,25 & 86,98 & 57,76 & 0,27 & 41,96 \\
Uruguay & 75,81 & 0,00 & 24,18 & 71,41 & 0,00 & 28,58 \\
\hline
\end{tabular}

FuENTE: Fondo Financiero parala cuenca del Plata, Red deTransporteIntermodal en el A rea Central dela Cuenca del Plata. Informe Final , UN PPRE / BID 740-OC/ Ar, Buenos Aires, 1997. 
CUADRO 5. Porcentajedel transportefluvial y marítimoen el comerciototal

delospaíses del MERCOSUR, Boliviay Chile, en toneladas, 1995.

\begin{tabular}{|l|c|c|}
\hline País & Exportaciones & Importaciones \\
\hline Argentina & 83,7 & 85,6 \\
Bolivia & 20,4 & 38,8 \\
Brasil & 96,0 & 88,5 \\
Chile & 95,5 & 74,0 \\
Paraguay & S/ d & 47,1 \\
Uruguay & 59,6 & S/ d \\
\hline
\end{tabular}

FUENTE: CEPAL, 1995.

IV. Muchos tramos viales están sujetos a la interrupción por varios motivos como lluvia, nieve u otros problemas, o están en proyectos, o cuando existen, son caminos de tierra.

$\checkmark$. Es deficiente la conservación de carreteras así como la señalización, lo que provoca inconvenientes en el movimiento de vehículos de transporte y carga, con el consiguiente incremento de los costos del flete.

VI. Las ferrovías y los puertos mantienen equipamientos y concepciones obsoletas, y muchos puentes carreteros fueron construidos para tecnologías que hoy no se corresponden.

VII. Muchas ferrovías están en mal estado de conservación, con trazados antiguos que establecen conexiones indirectas.

VIII. Las diferencias de trochas en las fronteras imponen dificultades para la circulación y para el transbordo, que desestimulan el uso de la línea férrea.

IX. En cuanto a los problemas de compatibilidad de trochas, por su importancia en el desarrollo de corredores interregionales, en general, el análisis de las principales características técnicas de los elementos de infraestructura de cada país muestra diferencias de especificaciones técnicas, diseño y ejecución entre vías y equipamientos de los diferentes países que son potencialmente vinculables. 
X. La continuidad de la red es un requisito fundamental para el rol en la integración de los países. Los ferrocarriles chilenos, bolivianos y brasileños cuentan en los ramales de conexión con el Ferrocarril General Belgrano con trocha métrica, lo cual facilita la continuidad de la red ferroviaria para una instancia de corredor bioceánico. ${ }^{4}$

XI. En los ferrocarriles existen, al igual que con la infraestructura vial carretera, inconvenientes por la posibilidad de circular durante todo el año por motivos climáticos, como en la red ferroviaria occidental boliviana, que se ve interrumpida anualmente en época de lluvias entre Cochabamba y La Paz.

XII. Los puertos, como el resto de la infraestructura de transportes, no tienen en su mayoría infraestructura operacional adecuada a los nuevos movimientos de comercio. Se han realizado al gunas mejoras necesarias acordes al aumento de la demanda.

XIII. El sistema marítimo y fluvial está recibiendo un fuerte impulso de la iniciativa privada. Surgen puertos privados amparados en la política de reforma del Estado.

XIV. Los puertos se especializan para operar con determinadas mercancías y tecnologías. Se vinculan a corredores de transporte, tratando de absorber las cargas de los centros mediterráneos.

${ }^{4}$ El punto de quiebre del sistema se produce en la Mesopotamia, donde la infraestructura del ferrocarril Mesopotámico, a diferencia de los anteriores, cuenta con trocha métrica, por lo que para dar continuidad a la conexión sería necesario extender un nuevo tramo entre la ciudad de Corrientes y algún paso de la frontera con Brasil, de trocha métrica, para integrarse con la red brasileña, o colocar un tercer riel entre Corrientes y Paso de los Libres, en una extensión de $452 \mathrm{~km}$. Además, se requerirá la construcción de un puente ferroviario sobre el río Paraná para unir la red del ferrocarril General Belgrano desde la ciudad de Resistencia en la provincia de Chaco, hasta la ciudad de Corrientes, en la provincia del mismo nombre. El río Paraná es el único corte en la traza bioceánica sobre el que no existe vinculación ferroviaria. Las redes occidental y oriental de Bolivia se vinculan a través de territorio argentino, existiendo una discontinuidad en el eje transversal Guaqui-La Paz-Puerto Quijarro entre las ciudades de Cochabamba y Santa Cruz de la Sierra; ello implica la necesidad de realizar un transbordo en este tramo a/ de camión, disponiéndose de operaciones precarias para dicha operación de interfase. 
$X V$. Funcional mente con el esquema resultante de esta primera fase de la reestructuración económica en el Cono Sur, el conjunto de estas vías asegura el acceso desde los centros consumidores y productores a puertos marítimos de los litorales Atlántico y Pacífico. El aumento en el tonelaje total transportado y en el tamaño de los buques tiende a la concentración en puertos que reúnen las mejores condiciones de funcionamiento y accesibilidad, llevando a una especialización y diferenciación de puertos adaptados a la operación con contenedores, granel y combustibles.

XVI. Los pasos fronterizos, en su mayoría, no están en condiciones para operar con la demanda actual, imponiendo demoras adicionales al transporte, situación que se verá agravada con el aumento del flujo de cargas, esta situación está vinculada a la agilización de la gestión de los trámites aduaneros en el cruce. XVII. Muchos pasos aún guardan indicios de la época de las políticas duras de frontera, sin coincidencia con las decisiones adoptadas en ambos lados de las fronteras.

XVIII. Si bien es importante la cantidad de pasos, los cruces se concentran en determinados puntos, no directamente vinculados a las características físicas de los mismos, sino a la de todo el corredor del que forman parte. Intentando nuevas alternativas, se han introducido mejoras u obras nuevas en cruces que todavía no se han visto reflejadas sustancialmente en los flujos. ${ }^{5}$

XIX. Las inversiones, las cuales escasas, así como los proyectos formulados, en su mayoría siguen concentrándose en los cruces existentes de mayor movimiento, y se direccionan a la optimización de la infraestructura existente, mejoras, ampliaciones de capacidad y modernización. La obra nueva en proporción es escasa, y con grandes subsidios y prebendas del Estado.

${ }^{5}$ Como ejemplo se puede citar el recientemente inaugurado puente internacional Santo Tomé-Sao Borja, entre Argentina y Brasil. Este nexo fue construido con el objetivo de descongestionar el tránsito por Uruguayana-Paso de los Libres, cosa que aún no ha podido concretarse. 


\section{REFLEXIONES FINALES}

Así como el modelo industrialista fordista tuvo su propio sistema de transporte y ambos configuraron patrones de localización, interacción espacial y estructuración territorial con una lógica determinada, el postfordismo o modelo de la economía flexible impulsado por las nuevas tecnologías y los cambios globales de la economía, está acompañado por una transformación sustancial en los sistemas de transporte, telecomunicaciones y redes informáticas, que implica nuevos patrones de localización y una nueva lógica territorial.

A partir del cambio del modelo de desarrollo, orientado ahora hacia una mayor apertura a nuevos mercados externos y basado en las exportaciones de productos diversos - con las modificaciones en las pautas de localización de actividades y con la aceleración que imponen los procesos de integración-, van surgiendo iniciativas para la realización de nuevas grandes obras públicas con nuevas modalidades de gestión y financiación.

El advenimiento de la actual fase de mundialización significa nuevos cambios en la división internacional del trabajo, aumentando la brecha entre los países centrales y las periferias subdesarrolladas, no sólo en materia de tecnología, sino en la participación en el comercio y en la producción a nivel mundial. Estos mismos fenómenos se despliegan, por medio de diferentes mecanismos, hacia el interior de cada país, generando alteraciones más o menos profundas en las economías regionales y en las relaciones entre los distintos sectores sociales.

Los objetos técnico-informacionales, señala Milton Santos (Santos-Silveira, 2001), se difunden más rápidamente hoy que en épocas pasadas de la división internacional del trabajo. Además, el área de influencia de los objetos actuales y de las acciones asociadas es más amplia, lo cual no depende tanto de los objetos como de las acciones que se concentran en ciertos puntos y áreas del país. Así, reconoce, por un lado, una "región concentrada", y por el otro, "apenas manchas y puntos de ese medio técnico-científico informacional, más o menos superpuestas a otras decisiones territoriales del trabajo en 
las metrópolis, capitales estaduales, capitales regionales, regiones agrícolas e industrias modernas".

El patrón de asentamiento productivo que está emergiendo facilita los procesos de segmentación geográfica de la cadena productiva, así como la desconcentración dentro de las empresas y, en general, crea un ambiente propicio para la descentralización en los ámbitos privado y público.

La revolución científica y tecnológica, como se ha mencionado, tiene efectos en las comunicaciones, reduciendo costos, al llevar virtualmente a cero la fricción del espacio en ciertos campos. También ha hecho posi ble, hoy en día, el contacto cara a cara mediatizado por la electrónica, avance que también juega a favor del incremento de la descentralización.

Los conceptos clásicos de accesibilidad e interacción espacial entre asentamientos, articulación territorial y complementariedad, trazado y evolución de las redes y relación espacio-tiempo-costo, se ven profundamente modificados por la dinámica espacial de la economía, los cambios introducidos por la nueva infraestructura de transporte y las redes en general, y la variación en las ventajas competitivas de los diferentes modos impulsados por los cambios tecnológicos y los nuevos modelos de gestión.

El orden económico actual parece estar caracterizado por la existencia de una alta concentración de la propiedad y el poder económico en un número reducido de empresas gigantes y un modelo de descentralización de la producción -la "economía difusa" - en el cual la fricción del espacio está dejando de ser un obstáculo para la acumulación.

Pero esta caracterización de las tendencias responde a situaciones que se verifican en las "áreas centrales del mundo". La situación en la periferia es diferente, ya que no existe el mismo nivel de desarrollo tecnológico y, fundamentalmente, ocupa un rol diferente en la división internacional del trabajo. La tendencia se expresa en la reconcentración de la producción y en la reaparición del fenómeno en la zona industrial, creada antes en muchos países.

La economía actual necesita de áreas continuas, dotadas de infraestructuras colectivas, pero este equipamiento llamado colectivo 
es, en verdad, hecho al servicio de las empresas hegemónicas, construidas con dinero público. Esas infraestructuras profundizan el uso selectivo del territorio, dejando excluidas o depreciadas a la mayor parte de la economía y de la población (Santos-Silveira, 2001).

En América Latina se estaría verificando la concentración de empresas para aprovechar los beneficios externos relacionados con el transporte y la minimización de los costos de transacciones entre las empresas. En general, son aglomeraciones jóvenes con pocas relaciones con el sistema local. En otros casos, se produce una tendencia mayor hacia la integración local integral entre otras empresas en el territorio definido, con la introducción de ciertos elementos de la especialización intrasectorial de empresas. En ambos casos, se favorece la formación de aglomeraciones urbanas a costa del resto del territorio, lo que agudiza aún más la situación de enorme concentración del potencial productivo y humano en las ciudades latinoamericanas. De esta manera, cobrarían aún mayor importancia las grandes aglomeraciones, en tanto mercados consumidores y concentradoras de servicios a las empresas, mientras que una nueva constelación de ciudades intermedias serviría de lugar de deslocalización de algunas de las actividades productivas antes concentradas en las grandes áreas industriales. Los flujos de inversiones operados a partir de empresas, privilegian las grandes metrópolis - São Paulo, Buenos Aires- y en menor medida algunas ciudades regionales - Curitiba, Porto Alegre, Córdoba - reforzando las jerarquías y polarizaciones espaciales. Los territorios y núcleos urbanos localizados próximos a las fronteras pocas veces son afectados por esos flujos.

A diferencia de las fases anteriores, en la actual fase de la mundialización el comando de los procesos no se realizaría a partir de un centro sino de una serie de "ciudades mundiales", articuladas en red, en el "archipiélago megapolitano mundial" (Velt, 1996; y Dollfur, 1997). En síntesis, se puede observar la tendencia a un centro difuso, en las áreas centrales del mundo, articulados en red con el resto del territorio, y una periferia concentrada, con posible articulación en su entorno inmediato, pero centralizada, sin articulación 
en red. Y el funcionamiento es en conjunto, forma parte de un mismo todo.

Así como este proceso de transformación acelerada de globalización y modernización vía integración no es homogéneo, tampoco lo es sobre los territorios y sociedades, donde aparecen regiones, sectores sociales y sectores productivos que se modernizan, que se incorporan al sistema de relaciones económicas y culturales a nivel mundial, que en términos real es se integran con economías vecinas, mientras que otras regiones y sectores sociales y productivos que quedan excluidos de este proceso.

El desarrollo geográfico desigual es parte esencial de la espacialidad capitalista, de su matriz espacial y de su topografía. Producido y reproducido en múltiples escalas, es inherente a la concretización de las relaciones sociales capitalistas y de las regionalizaciones, como medio/ presupuesto y como resultado/ encarnación (Soja, 1993). Incluso en las regiones relativamente más desarrolladas, no se trataría de una serie de procesos equilibrados, sino más bien de un conjunto de tendencias, no coordinadas, que expresan estas nuevas dinámicas.

En este marco, ciertas regiones lograrán integrarse en las redes mundiales -las "regiones que ganen"-, mientras que al mismo tiempo, al interior de esas regiones aparecerán fenómenos de polarización social. Por otro lado, en las regiones "que pierdan" en la competencia por la integración, estos fenómenos se verán todavía más acentuados.

Esa desigual dad puede aun crecer cuando se superpone la inserción previa que cada área tiene en el cuadro regional de su respectivo país, y la repercusión que pueden tener los flujos esparcidos desde los centros metropolitanos no será igual en cada caso, conforme a la integración diferenciada en el espacio nacional. ${ }^{6}$

${ }^{6} \mathrm{~A}$ sí, Milton Santos señala que la importancia del movimiento y la relativa desaparición de las distancias (para los conductores de flujos importantes) permitirá a algunos creer en la homogeneización del espacio. En verdad, el espacio se torna más diversificado y heterogéneo, y la división tradicional en regiones crece, produciendo vectores de modernidad y regulación. Milton Santos, Técnica, espacio y tiempo, Hucitec, Sao Paulo, 1994. 
Por otro lado, no existe planificación regional del sistema de transporte ni un plan estratégico global del transporte en la región que sintetice las políticas sectoriales existentes y permita contar con un marco de referencia y de orientación integrada de la gestión para dar respuesta a las necesidades de un moderno sistema de transporte. Se han introducido políticas de desregulación, concesiones, privatizaciones e inversiones, pero sin apuntar a un nuevo modelo que incluya una planificación integrada y estratégica del transporte dentro de una política regional en el marco de la integración.

Los problemas subregionales de transporte transcienden a la frontera de cada país y, por lo tanto, las soluciones deben ser pensadas con una visión amplia. No existe en la actualidad una visión de conjunto de la infraestructura subregional. En cada país se han adoptado criterios y patrones diferentes, así como distintas prioridades para las obras de infraestructura de interés subregional, preval eciendo siempre la visión local . ${ }^{7}$ Lo mismo puede detectarse en el plano interno de cada país, situación que junto al hecho antes comentado, genera la presencia de algunos proyectos compitiendo entre sí, o por lo menos requiriendo su compatibilización con la infraestructura de su área de influencia. Esta situación se ve agudizada por la crisis económica de la región.

Junto a la opinión socialmente aceptada está la de algunos actores locales que consideran la implantación de un proyecto de esta naturaleza constituye un elemento que potencia actividades locales y el desarrollo. Dentro de esta visión, frente a la falta de alternativas de inserción de grandes sectores de la población y de regiones en un proyecto de desarrollo, no se perciben los efectos negativos directos e indirectos de implantar estos nuevos proyectos sobre los territorios, o los subestiman. Esta situación es aprovechada por empresas transnacionales que no se pueden instalar fácilmente en países central es de tal manera que con el cebo de dar al gunos empleos, logran localizarse en el tercer mundo sin contar con programas de seguridad ambiental.

${ }^{7}$ Se debe destacar que, en casos específicos, existen comisiones binacionales o incluso multinacionales. 
Pero las transformaciones territoriales no deben considerarse sobre el medio natural exclusivamente, sino sobre el conjunto de las dimensiones social y económica. Existen problemas a solucionar y proyectos de gran envergadura que no pueden estar desconectados de una política territorial. Entre los proyectos más importantes y de gran impacto territorial pueden ser mencionados: la Hidrovía Paraguay-Paraná, el puente de baja altura Cristo Redentor, el puente Buenos Aires-Colonia, el puente Rosario-Victoria, los pasos cordilleranos, el ferrocarril Transandino Sur, entre otros que requieren estudios de fondo en el marco de lo que se propone. ${ }^{8}$

No se suele hacer hincapié en que el proyecto encuentra su plena justificación en un marco que excede lo local, y no se percibe el riesgo de que los beneficios sean canalizados por actores extrarregionales. Tampoco se llega a percibir el riesgo de que el territorio local quede, en el mejor de los casos, como soporte de una "tubería pasante".

Asimismo, si bien es cierto que resulta necesario aumentar el ritmo de inversiones en materia de infraestructura con el fin de superar el déficit histórico de modernización y mantenimiento, también es cierto que nos encontramos con una subutilización de cierta infraestructura existente. ${ }^{9}$

${ }^{8}$ Desde el sector gubernamental, la visión es heterogénea. Mientras que para algunos sectores el medio ambiente es el eje de su accionar político, para otros es un aspecto que aún se ve con desconfianza, por desconocimiento o por conflicto de intereses. En el sector empresarial, protagonista de la iniciativa privada asociada a las obras de infraestructura, es demasiado frecuente la consideración de la gestión ambiental como un mero trámite burocrático que se debe padecer y si es posible evitar.

${ }^{9}$ Como ejemplos se pueden citar, entre otros, el aumento de accidentes en rutas relacionados con la sobrecarga de las mismas por la discontinuidad de servicios ferroviarios de pasajeros en los corredores troncales, transfiriendo en tráfico a rutas no preparadas para este tránsito, y más aún en los últimos años con el aumento detráfico regional einternacional. La ruta nacional 14 dela M esopotamia argentina es un claro ejemplo. Antes de ser transformada en autopista como fue anunciado por las autoridades, sería conveniente utilizar toda la infraestructura del corredor, una vía ferroviaria en buen estado y un río navegable (como el Uruguay). 
La política de ordenación del territorio en relación con la planificación del transporte puede lograr una mejoría en las economías regionales y en la nacional. La infraestructura de transporte cumple un rol importante en la vertebración del territorio. Las nuevas transformaciones producen modificaciones en las condiciones de accesibilidad, revalorizando espacios y creando nuevas potencialidades de desarrollo en los centros de actividad económica. Está íntimamente ligada a la competitividad locacional del espacio geográfico.

Pero si bien la infraestructura de transporte es una factor necesario, no es suficiente para asegurar el desarrollo de un territorio. La relación transporte-territorio tiene efectos significativos sobre la competitividad, pero las obras de infraestructura no producen por sí solas un proceso de desarrollo, y tampoco éste puede darse sin aquéllas. Se trata de ambas cosas al mismo tiempo, lo que implica la necesidad de adoptar una visión global y territorial del problema, y siempre en el marco y a partir de un proyecto político que apunte a la mejora de la calidad de vida del conjunto de la población y a un proyecto de desarrollo en este sentido, y no meramente a convertir a los territorios en soporte funcional a intereses externos, tras un discurso moderno, y sin contemplar los efectos de las transformaciones que se operan sobre los mismos.

\section{BIBLIOGRAFÍA}

BID-INTAL. 1996. La infraestructura física en el Cono Sur. Buenos Aires.

Calcagno A. E. y Calcagno A. F. 1995. El universo neoliberal. Recuento de sus lugares comunes, Alianza Editorial, Buenos Aires.

Ciccolella, Pablo. 1994. “Integración y mundialización: claves de la reterritorialización capitalista en el Cono Sur de América Latina". Revista interamericana de planificación, Vol. XXVII, núm. 106. SIAP.

Dollfus, Olivier. 1997. La M ondialisation. Presses de Sciences Po (La Bibliothèque du citoyen), París. 
Fundación F. Ebert. 1991. A ntecedentes y perspectivas del M ercosur, Buenos Aires.

Gatto, Francisco. 1991. "La integración fronteriza en el proceso del Mercosur. Reflexiones a partir del caso del río Uruguay". En CIESU-FESUR Frontera, integración y después... El desarrollo regional integrado: un aspecto específico de la integración nacional. Montevideo.

Lipietz, Alain y Leborgne Daniele. 1991. “El posfordismo y su espacio". Realidad económica, núm. 122, Buenos Aires.

Pérez, Carlota. 1986. "Revoluciones tecnológicas y transformaciones socio-institucionales", En A. Cragnolini (comp.), Cuestiones de política científica y tecnológica. Seminario Jorge Sábato, Consejo Superior de Investigaciones Científicas, México.

Rofman, Alejandro y Cintia Russo. 1994. "Nuevo paradigma tecnoeconómico y el proceso de globalización y regionalización". Revista interamericana de planificación, vol. XXVII, núm. 106, SIAP.

Santos, Milton. 1994. Técnica, espacio y tiempo, Hucitec, Sao Paulo. Santos, Milton y María Laura Silveira. 2001. 0 Brasil. Território e sociedade no início do século XXI. En Editorial Record, 2oedición, Río de Janeiro.

Soja, Edward W. 1993. G eografías Pós-modernas. A reafirmaçao de espaço na teorias social crítica. Jorge Zahar Editor, Río de Janeiro.

Veltz, Pierre. 1996. M ondialisation, V illes et territoires. L'économie d'archipel. PUF (Economie en liberté), París. 